\title{
SLAVOJ ZIZEK: REAL, FANTASIA, OBJETOS SUBLIMES DA IDEOLOGIA, ATO POLÍTICO E EDUCAÇÃO
}

\author{
Hildemar Luiz Rech ${ }^{1}$
}

\begin{abstract}
Resumo:
Neste artigo é apresentada a visão de Zizek sobre a ideologia, o ato político e aspectos da educação. Para funcionar, não basta que a ideologia apareça como uma rede simbólica alienante amparada em aparelhos ideológicos, mas é necessário que ela também obtenha êxito em termos de interpelação subjetiva, mediante a incidência da fantasia inconsciente dos indivíduos sob a força aglutinadora da crença - via práticas apoiadas nos "objetos sublimes da ideologia". Porém, a ideologia não é apenas uma ilusão que preenche a lacuna de uma impossibilidade intrínseca, ela também funciona como uma forma de regular certa distância do encontro com o Real, com a Coisa. A ideologia sustenta, no nível da fantasia, o que procura evitar no nível da realidade. Por fim, um ato político, de ruptura radical com as coordenadas de um regime sócio-político opressor, representa também um ato educativo por excelência que aponta para a liberdade e a emancipação social.
\end{abstract}

Palavras-chave: Fantasia ideológica inconsciente; Objetos sublimes da ideologia; Ato político; Educação para a emancipação

\begin{abstract}
:
This article introduces Zizek's vision about ideology, political action and features of education. For getting effectiveness, it isn't enough that ideology turns up as an alienating symbolic network, supported by ideological apparatus, but it's necessary that it also gets success in terms of subjective questioning, by means of the incidence of individual unconscious fantasy, on the joining force of belief - by way of practices supported on the "sublime objects of ideology". However ideology is more than an illusion which fulfills the gap of some intrinsic impossibility. It also functions as a way to regulate certain distance to the encounter with the Real, with the Ding. Ideology sustains, on the level of fantasy, what it tries to avoid on the level of reality. Finally, a radical rupture political action with the coordinates of one oppressive socio-political regime represents also one educational action par excellence, which points to freedom and to social emancipation.
\end{abstract}

Key-words: Unconscious ideological fantasy; Sublime objects of ideology; Political action; Education to emancipation.

\footnotetext{
${ }^{1}$ Doutor em Ciências Sociais pelo IFCH da UNICAMP, SP, e pela Universidade de Manchester, Inglaterra; professor associado III no Depto. Fundamentos da Educação e no Programa de Pós-Graduação em Educação na FACED-UFC; pesquisador nos Programas PROCAD/CAPES e do LABOR/UFC. Integrante da linha de pesquisa e ensino "Filosofia e Sociologia da Educação", no eixo Filosofia, Política e Educação.
} 


\section{Introdução}

Ainda que uma ideologia não seja falsa, quanto a seu conteúdo positivo e consciente, ela pode manter sua função ideológica, pois o que importa realmente não é o conteúdo afirmado como tal pelo Sujeito do enunciado, mas o modo como este conteúdo se relaciona com a postura subjetiva inconsciente envolvida em seu próprio processo de enunciação. Desse modo, estamos no espaço da ideologia quando este conteúdo, seja ele falso ou verdadeiro, é funcional a uma relação de dominação ou exploração social não transparente, cuja eficácia situa-se justamente no caráter oculto de sua lógica de legitimação. Ademais, a ideologia também funciona como uma forma de regular certa distância do encontro com o Real, com a Coisa (ZIZEK, 1996A).

Já no que tange ao campo social, a crença, longe de ser um estado puramente mental, é sempre encarnada em nossa atividade social efetiva. Ou seja, a crença sustenta a fantasia que regula o funcionamento libidinal da realidade social (ZIZEK, 1996B).

\section{Uma breve explicação sobre dois conceitos psicanalíticos: O Real e a Coisa}

Para Zizek, o Real não pode ser confundido com a realidade, pois esta é construída simbolicamente, enquanto que o Real - mesmo que imanente ao Simbólico - é o resto que excede o simbólico, é o próprio princípio da distorção da realidade, enfim é núcleo traumático oculto que não pode ser simbolizado, mas que não cessa de deixar sua marca traumática nos furos da realidade simbolizada. O Real, portanto, não é nenhuma espécie de substancialidade consistente que aparece como pano de fundo da realidade, mas funciona muito mais como um núcleo traumático vazio que deixa a própria realidade - de modo incontornável mediada simbolicamente - distorcida e incompleta. Desse modo, o Real é o espectro do fantasma, que em si mesmo distorce a nossa percepção da realidade. Ademais, em seu nível mais radical o Real lacaniano, na interpretação de Zizek, é o X desmentido e repudiado, em nome do qual nossa visão da realidade é anamorficamente distorcida: ele é a Coisa (Ding) - o objeto primordial perdido - à qual o acesso direto não é possível e, ao mesmo tempo, o obstáculo que impede esse acesso direto, ou seja, ele é a Coisa que foge à nossa compreensão e a tela distorcedora que nos faz deixar de ver a Coisa. Em termos mais exatos, o Real, em última análise, é a própria mudança de ponto de vista, do primeiro para o segundo lugar na observação, que parece quase como uma antinomia kantiana que não pode ser

\begin{tabular}{|l|l|l|l|l|}
\hline Revista Dialectus & Ano 1 & n. 2 & Janeiro-Junho 2013 & p. 112-137 \\
\hline
\end{tabular}


resolvida em uma 'síntese dialética' mais elevada, mas que, ao contrário, eleva a sociedade à Coisa-em-si inacessível (cf. ZIZEK, 2008, p. 43-44; 2011, p. 139-140).

Entretanto, numa segunda abordagem, segundo Zizek, devemos apenas observar como essa antinomia radical, que parece impedir nosso acesso à Coisa, já é a própria Coisa, visto que a característica fundamental da sociedade de hoje é o antagonismo inconciliável entre a totalidade e o indivíduo. Isso significa que, em última análise, a condição do Real é puramente paralática e, como tal, não substancial: não tem em si nenhuma densidade sólida, é apenas a lacuna entre dois pontos de vista, perceptível apenas na passagem de um ao outro. O Real paralático, portanto, opõe-se à noção- padrão (lacaniana) do Real como aquilo que "sempre volta a seu lugar", ou seja, como aquilo que continua o mesmo em todos os universos (simbólicos) possíveis; o Real paralático é antes aquele que explica a própria multiplicidade de aparências do mesmo Real subjacente não é o núcleo rígido que persiste como o Mesmo, mas o osso duro do conflito, o núcleo oculto traumático que pulveriza a mesmice numa miríade de aparências. Num primeiro passo, o Real é o núcleo rígido impossível que não podemos confrontar diretamente, mas só pela lente de uma miríade de ficções simbólicas, de formações virtuais. Num segundo passo, esse mesmo núcleo rígido é puramente virtual, na verdade inexistente, um $\mathrm{X}$ que só pode ser reconstruído retroativamente a partir da miríade de formações simbólicas que é tudo o que realmente há (cf. ZIZEK, 2008, p. 43-44).

Portanto, o Real intervém por meio da anamorfose. Ou seja, o Real é o núcleo duro e oculto do antagonismo social que distorce a visão que as pessoas têm do antagonismo real na sociedade. Ou seja, o Real lacaniano não só é distorcido, como ele é o próprio princípio da distorção da realidade (cf. ZIZEK, 2011, p. 290-291).

As teorias das ciências positivas não refletem totalmente a realidade e não são apenas provadas por fatos, pois os 'fatos objetivos' aos quais se referem não são a realidade pré-simbólica, visto que esta é inacessível diretamente, o que significa que não se pode sair do conhecimento e do registro simbólico com a expectativa ingênua de abordar e entender diretamente a realidade sem a mediação das constelações da linguagem. Aliás, o núcleo traumático oculto da realidade - que não é a positividade do Real inacessível fora do Simbólico - é totalmente inerente ao Simbólico, pois é sua fissura ou impossibilidade imanente. Ou seja, o Real não é a realidade substancial transcendente que, de fora, perturba o equilíbrio simbólico, mas ele é o obstáculo imanente, a pedra no caminho do próprio Simbólico (cf. ZIZEK, 2011, p. 319-320).

\begin{tabular}{|l|l|l|l|l|} 
Revista Dialectus & Ano 1 & n. 2 & Janeiro-Junho 2013 & p. 112-137 \\
\hline
\end{tabular}


Conforme Zizek (2011), no registro do Real não falta nada, pois a falta é introduzida pelo Simbólico. É por isso que a negatividade não é o Real a minar o Simbólico de fora para dentro, mas o próprio Simbólico, o processo de simbolização com sua violenta abstração, com sua redução da riqueza da experiência ao traço unário (freudiano), significante que comporta a negatividade. Lacan inclusive se inspira em Hegel ao lembrar que a palavra é o assassinato da coisa (sache) que ela designa. Enfim, a forma elementar de negatividade não é o excesso de experiência além da simbolização, mas a própria lacuna que separa a simbolização da realidade vivenciada.

O Real lacaniano é mais reducionista que todas as estruturas simbólicas: nós o tocamos quando subtraímos de um campo simbólico toda a riqueza de suas diferenças, reduzindo-o a um mínimo de antagonismo. Isso se deve a esse estatuto "minimalista" puramente formal e insubstancial - do Real, em que, para Lacan, a repetição precede o recalque. Não é que, primeiro, recalcamos um conteúdo traumático e, depois, por sermos incapazes de lembrá-lo e, portanto, de esclarecer nossa relação com ele, esse conteúdo continua a nos perseguir, repetindo-se de forma disfarçada. Se o Real é a diferença mínima, então a repetição (que estabelece essa diferença) é primordial; a primazia do recalque surge com a "reificação" do Real numa Coisa (Ding) que resiste à simbolização - só então vemos que o Real excluído/recalcado insiste e repete-se. O Real, primordialmente nada mais é do que a lacuna que separa a Coisa de si mesma, a lacuna da repetição (cf. ZIZEK, 2011, p. 320-321).

Aqui ainda cabe observar que a Coisa, que é o núcleo do Real, está na origem da constituição do psiquismo. O nó entre Real e Simbólico é análogo ao nó que existe entre Lei e desejo, ou seja, a Coisa está na origem da instituição da Lei, enquanto Lei da palavra que não se resume à proibição, mas também envolve a lei positiva que ordena o desejo como verdade parcial, a partir da castração (do recalcamento).

Por outro lado, na última fase de sua produção teórico-psicanalítica, Lacan define a "pulsão de morte" como o próprio sistema simbólico que opera de forma autônoma, ignorando a realidade; finalmente, a "pulsão de morte" é concebida como o Real que resiste à simbolização, o Real permanece imanente ao Simbólico, como seu âmago traumático inerente: não há Real sem Simbólico, é o surgimento do Simbólico que introduz na realidade a lacuna do Real (cf. ZIZEK, 2011, p. 320).

Por outro lado, conforme as interpretações costumeiras e mais recorrentes sobre a teoria lacaniana referente à idéia de a Coisa (das Ding) é que, com base em Freud, esta é o objeto originário para sempre perdido da espécie humana, e que é visto como

\begin{tabular}{|l|l|l|l|l|} 
Revista Dialectus & Ano 1 & n. 2 & Janeiro-Junho 2013 & p. 112-137 \\
\hline
\end{tabular}


algo distinto do objeto perdido da história individual de cada sujeito, o objeto causa do desejo, designado por Lacan de "objeto pequeno a". Este último poderá ser reencontrado de alguma forma nos diversos objetos substitutos do desejo, constituídos ao longo da vida de cada sujeito, mas, no fundo destes objetos substitutos reaparecerá incessantemente $a$ Coisa originária perdida para sempre da espécie humana. No seminário VII, Lacan destaca que apesar de ser inassimilável, a Coisa serve de referência para o desejo, na medida em que permite ao aparelho psíquico atentar para o mundo das percepções. Enfim, a Coisa - que é algo vazio e apanhado como um furo na subjetividade - funciona como índice de exterioridade ou da realidade (cf. ZIZEK, 2006).

Segundo Zizek (2006, p. 84-85), cabe chamar atenção para o fato de que a visualização usual sobre a teoria de Lacan é de que ela tem um traço transcendentalista. Ou seja, nesta perspectiva enfatiza-se que, segundo Lacan, a entrada na Ordem simbólica comporta uma castração simbólica ou um recalcamento traumático, o que significa que o objeto primitivo do desejo se perde, transformando-se numa coisa impossível e ausente, que está para sempre perdida, a ponto de todo objeto empírico do desejo com que nos deparamos ser apenas um mero substituto suplementar do objeto primário perdido. Ou seja, a tese recorrente - mas problemática segundo Zizek - sobre Lacan é que o próprio fato da subjetividade significa que o objeto do desejo se perde e que a ilusão imaginária do sujeito, que se impõe aí, consiste precisamente na possibilidade de recuperar o objeto perdido, como forma de não aceitar o trauma da perda. Portanto, é aí que, segundo esta perspectiva de análise, se impõe a ilusão de tornar o 'Real impossível' possível, o que resultaria assim em uma suspensão da impossibilidade primordial de encontrar a Coisa (Ding). É também aí, contra todas essas tendências relativamente enganosas, que aparece a tese de diversos estudiosos lacanianos, segundo a qual temos de aceitar a perda primitiva como um a priori, pois, confrontar diretamente o Real da Coisa seria uma experiência incestuosa e autodestrutiva, insuportável e dolorosa demais pelo fato de o Real ser o Outro traumático ao qual nunca se pode responder adequadamente. Assim, a idéia de Real pressuposta aqui, é a do Real como impossível, no sentido da grande ausência: ele sempre nos falta, é um vazio básico, e a ilusão é que podemos recuperá-lo, mas isto é impossível porque o Real é traumático demais para ser encontrado e é por isso que temos que aceitar a perda primitiva como um a priori. Porém, para Zizek esta é uma tese problemática, embora não teoricamente errada (cf. ZIZEK, 2006). 
Para Zizek, o verdadeiro foco do Real lacaniano é que a idéia de "pulsão de morte" que está aí presente não pode ser interpretada nesses termos transcendentais, ou seja, em termos de uma perda a priori em que os objetos empíricos nunca coincidem com das Ding, a Coisa - com a lógica do Real como inexoravelmente impossível, uma idéia do objeto inatingível, marcado por um funcionamento do desejo estruturando-se em torno de um vazio primordial, ou seja, em termos de uma perda a priori em que os objetos empíricos do desejo não coincidem jamais com a Coisa (das Ding). Porém, conforme Zizek, além de aceitar a lacuna entre o vazio da Coisa e o objeto contingente que vem preenchê-la, é preciso considerar que a cisão não está entre a realidade empírica e a Coisa impossível, mas que o objeto do desejo está cindido nele mesmo, ou seja, a questão é que o objeto é ele mesmo e, ao mesmo tempo, é outra coisa: “A questão é que os objetos da pulsão são esses objetos privilegiados que, de algum modo, são um duplo deles mesmos. Lacan se refere a isso como la doublure [ o avesso, a outra face]. Há uma espécie de distância segura, mas é uma distância segura dentro do próprio objeto: não é a distância entre o objeto e das Ding" (ZIZEK, 2006, p. 86).

\section{Quando o "para-si”" da ideologia atua no cerne da realidade extra-ideológica}

Na contemporaneidade, como observa Zizek, em sua obra "Eles não sabem o que fazem: o sublime objeto da ideologia" (1992), apesar das declarações disseminadas de que vivemos um período histórico pós-ideológico, a ideologia não desapareceu do cenário político. Ao contrário, é por causa do seu sucesso que a ideologia pôde aparentemente ser descartada no cerne da opinião política hoje mais aceita.

Na sociedade do capitalismo contemporâneo os novos meios de comunicação de massa e eletrônico-cibernéticos facilitaram a penetração de conteúdos simbólicos, de marketing e de propaganda com substrato ideológico em todos os poros da sociedade, conduzindo ao enfraquecimento do próprio peso da ideologia, de modo que hoje os indivíduos não agem mais prioritariamente em função de suas crenças e convicções, sendo que a reprodução do sistema se dá muito mais via sujeição osmótica às premissas da sociedade de consumo e do espetáculo, e via eficácia da coerção e da aplicação das normas legais e de controle estatais adequadas aos interesses do capital globalizado. Nestas circunstâncias as coisas ficam bem mais opacas e embaralhadas, pois um campo obscuro, em que a realidade torna-se indistinguível da ideologia, impõe-se, de modo que o "para-si" da ideologia entra em ação no cerne da realidade extra-ideológica.

\begin{tabular}{|l|l|l|l|l|} 
Revista Dialectus & Ano 1 & n. 2 & Janeiro-Junho 2013 & p. 112-137 \\
\hline
\end{tabular}


Este novo quadro sócio-econômico, político e cultural, contudo, não significa a emergência de uma realidade que aponta para o desaparecimento da ideologia, pois os mecanismos de coerção econômica e de coação da norma legal sempre mobilizam e materializam crenças que são implicitamente ideológicas. Assim, por exemplo, o direito à inviolabilidade da propriedade capitalista implica a crença de que isso é um pressuposto inquestionável para o pleno funcionamento da sociedade. Ademais, segundo Zizek (1996A), a forma de consciência reflexiva que se adéqua à chamada sociedade "pósideológica" do capitalismo tardio continua a ser, strictu sensu, um comportamento ideológico, pois implica uma série de pressupostos ideológicos sobre a relação entre os "valores" e a "vida real", necessários à reprodução das relações sociais existentes. Assim, a atitude cínica, que se mostra indiferente frente às expressões ideológicas mais patéticas, preferindo dar importância apenas às suas motivações consumistas, utilitaristas e hedonistas, não escapa deste tipo de incidência ideológica.

No ambiente capitalista tardio emerge, portanto, um contingente "sui generis" de fenômenos ideológicos que difere da ideia de ideologia como doutrina explícita - com convicções e valores articulados sobre as características do homem, da sociedade e do universo - e que é diferente também da ideologia em sua existência material mediante as instituições, rituais e práticas que lhe dão corpo. Trata-se, enfim, de uma rede elusiva e esquiva de pressupostos e atitudes implícitos, quase "espontâneos", que formam um momento irredutível da reprodução de práticas "não ideológicas" (econômicas, legais, políticas, sexuais, etc.), representando a noção marxista de "fetichismo da mercadoria" um destacado exemplar para este tipo de fenômeno ideológico.

A propósito, segundo Zizek (1996A, p. 21):

\footnotetext{
A noção marxista de "fetichismo da mercadoria" (...) designa, não uma teoria burguesa da economia política, mas uma série de pressupostos que determinam a estrutura da própria prática econômica [efetiva] das trocas de mercado - na teoria, o capitalista agarra-se ao nominalismo utilitarista, mas, na prática da troca etc., segue 'caprichos teológicos' e age como um idealista especulador. Por essa razão, a referência direta à coerção extra-ideológica (do mercado, por exemplo) é um gesto ideológico por excelência: o mercado e os meios de comunicação (de massa) estão dialeticamente interligados; vivemos numa 'sociedade do espetáculo' (Guy Debord) em que a mídia estrutura antecipadamente nossa percepção da realidade e a torna indiscernível de sua imagem 'esteticizada'.
} 


\section{O elemento espectral, o Real do antagonismo, o fetichismo da mercadoria, a luta de classes e a ideologia}

Ademais, quando se analisa criticamente a complexidade dos fenômenos ideológicos contemporâneos, deve ser levado em consideração também o elemento espectral e o Real do antagonismo que os acompanha, em sua operação puramente formal que promove o efeito de profundidade da ideologia. Estes fatores, talvez constituam, segundo Zizek (1996A), a célula elementar ou a expressão mais pura da ideologia e que tem estreita ligação como o conceito lacaniano de Significante Mestre (S1), que representa a dimensão verdadeiramente essencial e fundamentalmente inconsciente, sobre a qual não é preciso fazer nenhuma afirmação positiva, pois o S1 é um significante sem significado, que, entretanto, de forma desmedida faz parte da ordem simbólica como tal, obrigando a localização da ideologia na lacuna entre as afirmações positivas da 'cadeia comum de significantes' e os lapidares e emblemáticos 'significantes Mestres' vazios de significado. Mesmo que não haja nenhuma linha demarcatória evidente que separe a ideologia da realidade e embora a ideologia já esteja imperceptivelmente em ação em tudo o que é vivido como realidade, ainda assim se mantém uma tensão entre ambas que confere uma atualidade à crítica da ideologia.

De outro lado, segundo Zizek (1996A), Karl Marx concebeu a ideologia como uma máquina radicalmente não espontânea, que distorce de fora para dentro a autenticidade da nossa experiência de vida. Desse modo, a ideologia só surge quando as ideias distorcidas perdem seu caráter imediato e são sofisticadamente elaboradas por ‘intelectuais orgânicos' a fim de servir de legitimação das relações de dominação e de exploração existentes. Em consequência, nesta perspectiva, a ideologia propriamente dita só surge com a divisão do trabalho, a cisão das classes sociais e o estado moderno. Sob este prisma, a ideologia não brota da 'vida em si', mas só passa a existir na medida em que a sociedade é regulada por um Estado atrelado às relações sociais capitalistas. Ou seja, para Marx, o "fetichismo da mercadoria" não integra o universo da ideologia, mas mesmo assim, este elemento idolátrico falso, esta fantasia teológica, este "elemento espectral obsceno", que acompanha a matéria espiritualizada da mercadoria, enfim, este universo "sui generis" da mercadoria proporciona o suplemento fetichista necessário à doutrina oficial, sendo a sua base real a idolatria do Bezerro de ouro, o dinheiro, entronizado ilusoriamente como tendo propriedades especiais e sublimes, independentes das relações sociais de força, de exploração e de dominação na sociedade.

\begin{tabular}{|l|l|l|l|l|} 
Revista Dialectus & Ano 1 & n. 2 & Janeiro-Junho 2013 & p. 112-137 \\
\hline
\end{tabular}


Por sua vez, também Jacques Derrida, em seu livro "Espectros de Marx", apresentou uma importante reflexão ao empregar o termo "espectro" para indicar a fugidia pseudo-materialidade que subverte as oposições ontológicas clássicas entre realidade e ilusão. Este aspecto talvez represente o cerne pré-ideológico ou a matriz formal em que são enxertadas as diversas formações ideológicas, tendo em vista que o círculo da realidade somente pode ser fechado mediante um estranho suplemento espectral. Mas, por que o elemento espectral é indissociável da existência da realidade? A propósito, segundo Zizek:

Lacan fornece uma resposta precisa e essa pergunta. [Ou seja,] (o que vivenciamos como) realidade não é a "própria coisa”, é sempre já simbolizado, constituído e estruturado por mecanismos simbólicos - e o problema reside no fato de que a simbolização, em última instância, sempre fracassa, jamais consegue "abarcar" inteiramente o "real", sempre implica uma dívida simbólica não quitada, não redimida. Esse "real" (a parte da realidade que permanece não simbolizada) retorna sob a forma de aparições espectrais. Conseqüentemente, não se deve confundir "espectro" com "ficção simbólica", com o fato de que a realidade em si tem a estrutura de uma ficção, por ser simbolicamente (ou como dizem alguns sociólogos, "socialmente") construída; as noções de espectro e ficção (simbólica) são co- dependentes em sua própria incompatibilidade (...). Dito de maneira simples, a realidade nunca é diretamente "ela mesma"; só se apresenta através de sua simbolização incompleta e falha. As aparições espectrais emergem justamente nessa lacuna que separa perenemente a realidade e o "real", e em virtude da qual a realidade tem o caráter de uma ficção (simbólica): o espectro dá corpo àquilo que escapa à realidade - simbolicamente estruturada (ZIZEK,1996A, p. 26).

Sob esta perspectiva crítica, a aparição espectral, que preenche o buraco do "Real" em relação à realidade (que como tal nunca é toda), consiste no cerne pré- ideológico da ideologia. Para que possa emergir aquilo que vivenciamos como "a realidade", algo tem que ser "foracluído" dela. Ou seja: "A realidade, tal como a verdade, nunca é, por definição, 'toda'. O que o espectro oculta não é a realidade, mas seu 'recalcamento primário', o X irrepresentável em cujo 'recalcamento' fundamenta-se a própria realidade” (ZIZEK, 1996A, p.26).

A própria elaboração consequente do conceito de luta de classes no capitalismo, por exemplo, nomeia o "real" traumático do antagonismo que impede a realidade social objetiva de se constituir como um todo fechado em si mesmo:

O grande paradoxo da noção de 'luta de classes' é que a sociedade 'mantémse coesa' pelo próprio antagonismo ou cisão que impede permanentemente seu fechamento num Todo harmonioso, transparente e racional - justamente pelo empecilho que mina qualquer totalização racional. Embora a 'luta de classes' não esteja diretamente dada (...) como uma entidade positiva, ela funciona, em sua própria ausência [imediata], como ponto de referência que nos permite situar qualquer fenômeno social (...), ao concebê-lo como mais

\begin{tabular}{|l|l|l|l|l|}
\hline Revista Dialectus & Ano 1 & n. 2 & Janeiro-Junho 2013 & p. 112-137 \\
\hline
\end{tabular}


outra tentativa de remendar a brecha do antagonismo entre as classes, de apagar seus vestígios (ZIZEK, 1996A, p. 26).

Desse modo, a luta de classes faz parte do "Real" porque é "foracluída" do todo simbolizado, no sentido lacaniano restrito. Ou seja, ela é um empecilho ou uma dificuldade que origina simbolizações sempre renovadas, mediante as quais não são medidos esforços para preencher os furos que não cessam de se reinscrever na realidade a partir deste nó, tentando-se, desse modo, integrar ou domesticar a própria luta de classes, a fim de evitar seu núcleo traumático. De acordo com esta perspectiva restrita:

A luta de classes não é nada mais do que o nome do limite imperscrutável que
é impossível de objetivar, situado dentro da totalidade social, já que ela mesma
é o limite que nos impede de conceber a sociedade como uma totalidade
fechada. Ou [seja], (...) a "luta de classes" designa o ponto em relação ao qual
"não existe metalinguagem": na medida em que toda posição dentro do todo
social é sobredeterminada, em última instância, pela luta de classes, não está
excluído da dinâmica desta última nenhum lugar neutro de onde seja possível
localizá-la dentro da totalidade social (ZIZEK, 1996A, p. 27).

Desse modo, segundo Zizek (1996A), a situação paradoxal da luta de classes pode também ser articulada mediante a crucial distinção hegeliana entre Substância e Sujeito. Assim, a luta de classes envolve o plano social objetivo em nível da Substância, funcionando, desse modo, apenas como uma indicação secundária de uma contradição mais basilar neste processo, uma desarmonia incômoda regulada por mecanismos positivos que independem da luta de classes e que estão relacionados aos problemas intrínsecos ao desenvolvimento das forças produtivas, sendo que nesta perspectiva a luta de classes irrompe como uma decorrência da contradição e da inadequação entre o estágio de desenvolvimento das forças produtivas e das relações sociais de produção. Mas, quando passamos para o nível do Sujeito percebemos que a luta de classes não é o efeito de um mero processo objetivo, mas já está sempre atuante no próprio cerne desse processo. Ou seja, o valor da força de trabalho em si não é objetivamente dado, mas resulta da própria luta de classes e é no cerne desta luta que os capitalistas criam novos meios de produção com nova base tecnológica, visando reduzir o valor relativo e absoluto da força de trabalho. Portanto, não é possível isolar nenhuma dinâmica social objetiva que não implique a presença subjetiva da luta de classes. "A própria 'paz', a ausência da luta, já é uma forma de luta, é a vitória (temporal) de um dos lados da luta. [Ou seja], (...) a própria invisibilidade da luta de classes (...) já é um efeito (...) da hegemonia exercida por um lado da luta" (ZIZEK, 1996A, p. 28). 
Por outro lado, ao se considerar a interpretação da luta de classes na perspectiva lacaniana de um antagonismo social integrando o "Real", que não faz parte de modo explícito da realidade social objetiva, emerge a compreensão de que a própria constituição da realidade social implica o "recalcamento primário" de um antagonismo. Assim, “... o esteio fundamental da crítica da ideologia - o ponto de referência extra- ideológico que nos autoriza a denunciar o conteúdo de nossa experiência imediata como 'ideológico' não é a 'realidade', mas o 'Real' recalcado do antagonismo" (ZIZEK, 1996A, p. 30). Ou seja, o que emerge das distorções da representação exata da realidade é o "Real", o trauma em torno do qual se estrutura a realidade social. Assim: "A 'realidade' em si, na medida em que é regulada por uma ficção simbólica, oculta o 'Real' de um antagonismo - e é esse 'Real', foracluído da ficção simbólica, que volta sob a forma de aparições espectrais"' (ZIZEK, 1996A, p. 32).

Em Karl Marx, por exemplo, na análise do "segredo da forma-mercadoria" é importante o desmascaramento do sentido oculto, por trás da forma-mercadoria, pois o valor de uma mercadoria não depende do puro acaso de uma interação acidental entre a oferta e a procura, por exemplo. Mas isto não basta, pois a própria economia política burguesa clássica já descobrira o segredo da forma-mercadoria. Então o verdadeiro segredo não é o segredo por trás da forma, mas o segredo da própria forma, sua gênese e a prática que cria esta forma. Ou seja, a economia política clássica nunca se perguntou: "Por que esse conteúdo assumiu tal forma particular, isto é, por que o trabalho se expressa num valor, e por que a mensuração do trabalho por sua duração se expressa na magnitude do valor produto?” (SOHN-RETHEL apud ZIZEK, 1996B, p. 301).

\section{O alcance universal da forma-mercadoria}

Segundo Zizek (1996B), o estudioso que apresentou a reflexão mais aprofundada quanto ao alcance universal da forma-mercadoria foi Alfred Sohn-Rethel, integrante da Escola de Frankfurt. Segundo este interprete, não somente a chave da crítica da economia política, o segredo oculto do valor trabalho, integra a análise formal da mercadoria, mas também o elemento fulcral da explicação histórica do modo de pensamento conceitual abstrato e da divisão entre trabalho intelectual e manual, que passou a existir juntamente com ele. Desse modo, nas palavras de Zizek, o esqueleto do próprio sujeito transcendental kantiano - isto é, a rede de categorias transcendentais que constitui o arcabouço a priori do conhecimento científico "objetivo" é articulada de

\begin{tabular}{|l|l|l|l|l|}
\hline Revista Dialectus & Ano 1 & n. 2 & Janeiro-Junho 2013 & p. 112-137 \\
\hline
\end{tabular}


antemão pela própria estrutura da forma-mercadoria. O paradoxo da forma-mercadoria, esse fenômeno patológico intramundano, em linguagem kantiana, consiste em ela fornecer-nos uma senha de acesso para solucionar a questão fundamental da teoria do conhecimento: Como é possível um conhecimento objetivo com validade universal?

Posteriormente, a série de análises de Sohn-Rethel levou à seguinte conclusão:

\begin{abstract}
O método científico (o da ciência newtoniana da natureza) pressupõe um aparato de categorias, uma rede de noções através das quais ele capta a natureza; tal aparato já está presente na efetividade social, já está em ação no ato da troca da mercadoria. Antes que o pensamento pudesse chegar à pura abstração, a abstração já atuava na efetividade social do mercado. A troca de mercadorias implica uma dupla abstração: a abstração do caráter mutável da mercadoria durante o ato de troca e a abstração do caráter concreto, empírico, sensorial e particular da mercadoria (SOHN-RETHEL apud ZIZEK, 1996B, p. 302).
\end{abstract}

Portanto, o sine qua non da ciência moderna, expresso na quantidade pura, já estava em ação no dinheiro - essa mercadoria que possibilita a comensurabilidade do valor de todas as outras mercadorias, a despeito de sua determinação qualitativa particular -, antes que o próprio pensamento pudesse chegar à idéia de uma determinação puramente quantitativa. O ato social da troca já havia realizado um movimento abstrato "puro" mediante a transferência de propriedade das mercadorias, deixando totalmente intactas as propriedades sensório-concretas do objeto apanhado em movimento, antes que a física pudesse articular a noção de um movimento puramente abstrato, ocorrendo num espaço geométrico, independentemente de quaisquer determinações qualitativas dos objetos em movimento. Ou seja, na efetividade social do mercado, as moedas sempre foram tratadas como se elas consistissem numa substância imutável e sublime, em relação à qual o tempo não exerce nenhum poder e que se situa num contraste antitético com qualquer material encontrado na natureza. A propósito:

O sujeito transcendental, esteio da rede de categorias a priori, confronta-se com o fato inquietante de que depende, em sua própria gênese formal, de um processo "patológico" intramundano - um escândalo, uma impossibilidade absurda do ponto de vista transcendental, na medida em que o a priori formaltranscendental é, por definição, independente de todos os conteúdos positivos: um escândalo perfeitamente correspondente ao caráter escandaloso do inconsciente freudiano, que também é intolerável do ponto de vista transcendental-filosófico. Ou seja, se examinarmos de perto o status ontológico do que Sohn-Rethel chama de "abstração real" [das reale Abstraktion] (isto é, o ato de abstração que opera no próprio processo efetivo da troca de mercadorias), verificaremos ser impressionante a homologia entre seu status e o do inconsciente, dessa cadeia significante que persiste numa "outra Cena": a "abstração real" é o inconsciente do sujeito transcendental, o suporte do conhecimento científico objetivo-universal (ZIZEK, 1996B, p. 302-303). 
Segundo Zizek (1996B), o problema de qual é o caráter material sui generis do dinheiro não foi solucionado por Karl Marx. Aqui evidentemente não se trata da matéria empírica de que o dinheiro é feito, mas do material sublime, daquele outro corpo intocável e não degradável que persiste para além do corpo físico. Zizek observa o seguinte a este respeito:

\begin{abstract}
Esse outro corpo do dinheiro é como o cadáver da vítima sádica, que suporta todas as torturas e sobrevive com sua beleza imaculada. Essa corporalidade imaterial do 'corpo dentro do corpo' dá-nos uma definição precisa do objeto sublime, e é somente nesse sentido que a idéia psicanalítica do dinheiro como um objeto 'pré-fálico', 'anal', é aceitável - desde que não nos esqueçamos de como essa existência postulada do corpo sublime depende da ordem simbólica [da injunção do 'Grande Outro'] (ZIZEK, 1996B, p. 303-304).
\end{abstract}

Ou seja a injunção de que a moeda deve servir como meio de troca e não como objeto de uso está estampado no corpo da própria moeda. E a autoridade emitente assegura a reposição plena do peso e da pureza metálica da moeda quando esta é atingida pelo desgaste da circulação. "Sua matéria física tornou-se, visivelmente, mera portadora de sua função social" (SOHN-RETHEL apud ZIZEK, 1996B, p. 304).

A abstração da troca não tem nada a ver com as propriedades efetivas de um objeto e, como tal, não se trata de uma "abstração do pensamento" que ocorre no interior do sujeito pensante. A abstração pertinente ao ato de troca é irredutivelmente exterior e descentrada. Ou seja: “A abstração da troca não é o pensamento, mas tem a forma do pensamento" (SOHN-RETHEL apud ZIZEK, 1996B, p. 304).

Segundo Zizek, a forma de pensamento apresenta um status ontológico que não é o do pensamento porque é externa a ele, constituída por uma "Outra Cena”, mediante a qual a forma já é externamente articulada de antemão. E essa forma, anterior e externa ao pensamento, é, em suma, a ordem simbólica, que precisamente é “(...) uma ordem formal desse tipo que suplementa e/ou rompe a relação dual da realidade factual externa com a experiência interna" (SOHN-RETHEL apud ZIZEK, 1996B, p. 304).

Portanto, a abstração da troca não pode ser concebida como um processo que ocorre no campo do conhecimento por que a forma de pensamento que envolve a abstração é anterior e externa ao pensamento, integrando a ordem simbólica.

A relação entre a efetividade social da troca de mercadorias e a consciência dela envolve um paradoxo crucial que consiste no seguinte: o não-conhecimento da realidade é parte da própria essência dessa relação. Ou seja, se viéssemos a 'saber demais', a ponto de ficarmos totalmente cientes do verdadeiro funcionamento da realidade social, essa realidade se dissolveria.

\begin{tabular}{|l|l|l|l|l|} 
Revista Dialectus & Ano 1 & n. 2 & Janeiro-Junho 2013 & p. 112-137 \\
\hline
\end{tabular}


Essa, provavelmente é a dimensão fundamental da 'ideologia', pois a ideologia não é simplesmente uma 'falsa consciência', uma representação ilusória da realidade; antes, é essa mesma realidade que já deve ser concebida como 'ideológica'.

Segundo Zizek (1996B, p. 305-306):

"Ideológica" é uma realidade social cuja própria existência implica o nãoconhecimento dos participantes, ou seja, a efetividade social cuja própria reprodução implica que os indivíduos "não sabem o que fazem". "Ideológica" não é a "falsa consciência" de um ser (social), mas esse próprio ser, na medida em que ele é sustentado pela 'falsa consciência'.

\title{
Como Marx inventou o sintoma?
}

De modo semelhante, outra formação cuja consistência e funcionamento implica um certo não-conhecimento por parte do sujeito é a dimensão do sintoma, pois o sujeito somente pode gozar com o sintoma se a lógica deste lhe escapa. Tendo em conta isto, Zizek (1996B) então se pergunta de como podemos definir o sintoma marxista?

A partir de uma perspectiva lacaniana, Marx "inventou o sintoma" mediante a identificação de uma fissura, de uma assimetria, de um certo desequilíbrio patológico que desmente o universalismo dos "direitos e deveres burgueses". Longe de estabelecer o anúncio de uma realização parcial e ainda inacabada dos direitos e deveres universais, esse desequilíbrio funciona como o próprio momento constitutivo desse universalismo. Ou seja, o sintoma, no sentido estrito, é um mecanismo particular que subverte seu próprio fundamento universal. Como argumenta Zizek, a este respeito:

\begin{abstract}
Esse processo implica, pois, uma certa lógica da exceção: todo Universal ideológico - por exemplo, a liberdade, a igualdade - é "falso", na medida em que necessariamente inclui um caso específico que rompe sua unidade, que expõe sua falsidade. A liberdade, por exemplo: é uma noção universal que abrange várias espécies (liberdade de fala e de imprensa, de consciência, de comércio, [civil] política, etc.), mas também, por uma necessidade estrutural, uma liberdade específica (a de o trabalhador vender livremente sua força de trabalho no mercado), que subverte essa noção universal. Ou seja, essa liberdade é o próprio oposto da liberdade efetiva: ao vender "livremente" sua força de trabalho, o trabalhador perde sua liberdade - o conteúdo real desse livre ato de venda é a escravização do trabalhador ao capital. O aspecto crucial é que essa liberdade paradoxal, a forma de seu oposto, é precisamente o que fecha o círculo das "liberdades burguesas" (ZIZEK, 1996B, p. 306).
\end{abstract}

O ideal do mercado capitalista que é a chamada "troca de equivalentes", apresenta uma lógica de exceção semelhante. A propósito, tão logo que prevalece a produção para o mercado na sociedade, emerge de modo disseminado um novo tipo de mercadoria que é a força de trabalho, como resultado da necessidade dos trabalhadores de a venderem no mercado para a sua própria sobrevivência.

\begin{tabular}{|l|l|l|l|l|} 
Revista Dialectus & Ano 1 & n. 2 & Janeiro-Junho 2013 & p. 112-137 \\
\hline
\end{tabular}


Porém, com essa nova mercadoria a troca de equivalentes torna-se uma negação, por que a força de trabalho apresenta uma peculiaridade oculta, cujo uso produz a "maisvalia", um excedente que ultrapassa o valor contratado da força de trabalho e é apropriado pelos capitalistas. Como observa Zizek (1996B, p. 307) a este respeito:

\begin{abstract}
Aqui temos, mais uma vez, um certo Universal ideológico (o da troca eqüitativa de equivalentes) e uma troca paradoxal particular (a da forca de trabalho por seus salários) que, precisamente como um equivalente, funciona como a própria forma de exploração. O desenvolvimento "quantitativo" em si, a universalização da produção de mercadorias, promove uma nova "qualidade", a emergência de uma nova mercadoria que representa a negação interna do princípio universal da troca equivalente de mercadorias: em outras palavras, ela acarreta um sintoma (...), [o ponto de exceção que funciona como negação interna do princípio universal da troca equivalente de mercadorias].
\end{abstract}

Aliás, é com base neste paradoxo que Marx tece uma acerbada crítica à noção hegeliana da sociedade como uma totalidade racional, apontando o proletariado como o ponto em que a Razão incorporada na sociedade moderna vigente nutre a sua desrazão.

Ainda no que se refere ao "fetichismo da mercadoria" cabe observar que apenas em uma primeira aproximação ele é "uma relação social definida entre os homens, que assume aos olhos deles a forma fantasiosa de uma relação entre coisas". Em seu funcionamento efetivo, o valor das mercadorias é uma insígnia de uma rede de relações sociais que assume uma propriedade quase "natural" de outra coisa-mercadoria que é o dinheiro. Desse modo, o aspecto central do "fetichismo da mercadoria" não consiste em uma relação fantasiosa de coisas, mas antes, numa determinada inconsciência (desconhecimento) da relação entre um elemento particular e uma rede estruturada de elementos da qual ela é seu elemento paradoxal de articulação. "Aquilo que é realmente um efeito estrutural, um efeito da rede de relações entre os elementos, aparece como uma propriedade imediata de um dos elementos, como se essa propriedade também lhe pertencesse fora de sua relação com os outros elementos” (ZIZEK, 1996B, p. 308).

Em sua argumentação sobre o "fetichismo da mercadoria", Marx observa uma homologia entre uma mercadoria A e outra mercadoria B, sendo esta somente um equivalente na medida em que A se relaciona com B "como sendo a "forma da aparência" de seu próprio valor, somente dentro dessa relação. Zizek emenda a seguinte observação, introduzindo uma maior complexidade para esta linha de argumentação:

Mas a aparência - e nisso consiste o efeito de inversão que é característica do fetichismo -, a aparência é exatamente oposta: A parece relacionar-se com B como se, para B, ser um equivalente de A não correspondesse a ser uma "determinação reflexiva" (Marx) de A - ou seja, como se B já fosse, em si mesmo, equivalente a A; a propriedade de ser "equivalente" parece pertencer-

\begin{tabular}{|l|l|l|l|l|} 
Revista Dialectus & Ano 1 & n. 2 & Janeiro-Junho 2013 & p. 112-137 \\
\hline
\end{tabular}


lhe até mesmo fora de sua relação com A, no mesmo nível de suas outras propriedades efetivas "naturais" que constituem seu valor de uso (ZIZEK, 1996B, p. 309).

A teoria lacaniana do estádio do espelho apresenta uma forma de elaboração semelhante. Somente na medida em que outro ser humano oferece a imagem de unidade ao eu (moi), ou seja, somente quando o eu se refletir num outro é que ele pode chegar à sua auto-identidade, de modo que a identidade e a alienação são estritamente correlatas.

Retomando aqui a análise do pensamento de Marx, cabe estabelecer uma ponderação mais clara sobre a sua descoberta da dimensão do sintoma. A relação Senhor e Escravo, dominante no contexto das relações servis de dominação, passou por um determinado tipo de deslocamento no capitalismo. A desfetichização das relações entre os homens ocorreu como se sua efetivação devesse que ser paga com o fetichismo nas "relações entre as coisas". Desse modo, desapareceu a transparência imediata das relações sociais mais cruciais, as de produção. Assim, o lugar do fetichismo apenas se desloca das relações intersubjetivas e interpessoais para as relações entre mercadorias, enfim entre os produtos do trabalho. Então, é na maneira como Marx abordou a passagem do feudalismo para o capitalismo é que ocorre a descoberta do sintoma. A propósito como argumenta Zizek (1996B, p. 310):

Com o estabelecimento da sociedade burguesa, as relações de dominação e servidão são recalcadas: formalmente, parecemos estar lidando apenas com sujeitos livres, cujas relações interpessoais estão isentas de qualquer fetichismo; a verdade recalcada - a da persistência da dominação e da servidão - emerge num sintoma que subverte a aparência ideológica de igualdade, liberdade e assim por diante. Esse sintoma, o ponto de emergência da verdade sobre as relações sociais, são precisamente as "relações sociais entre as coisas": "Em vez de aparecer em quaisquer circunstâncias como suas próprias relações [intersubjetivas], as relações sociais entre os indivíduos disfarçam-se sob a forma de relações sociais entre as coisas" - aí temos uma definição precisa do sintoma histérico, da "histeria de conversão" que é própria do capitalismo.

\section{Como a razão cínica deixa intacto o nível fundamental da fantasia ideológica, o nível em que a ideologia estrutura a própria realidade social}

Em sua obra "Crítica da Razão Cínica”, Peter Sloterdijk estabelece a observação de que o modo dominante de funcionamento da ideologia é cínico, o que tornaria impossível o clássico método crítico-ideológico. Porém, para Zizek (1996B, p. 313):

O sujeito cínico tem perfeita ciência da distância entre a máscara ideológica e a realidade social, mas, apesar disso, continua a insistir na máscara. A fórmula, portanto, tal como proposta por Sloterdijk, seria: "eles sabem muito bem o que estão fazendo, mas mesmo assim o fazem” [e não a fórmula de

\begin{tabular}{|l|l|l|l|l|}
\hline Revista Dialectus & Ano 1 & n. 2 & Janeiro-Junho 2013 & p. 112-137 \\
\hline
\end{tabular}




\begin{abstract}
Marx em o Capital: “disso eles não sabem, mas o fazem”]. A razão cínica já não é ingênua, mas é o paradoxo de uma falsa consciência esclarecida: sabese muito bem da falsidade, tem-se plena ciência de um determinado interesse oculto por trás de uma universalidade ideológica, mas, ainda assim, não se renuncia a ela.
\end{abstract}

Ou seja, o cinismo reconhece e leva em conta o interesse particular que acompanha a universalidade ideológica, mas mesmo assim ainda encontra justificativas para conservar a máscara. Portanto, frente à razão cínica já não funciona mais submeter o texto ideológico a uma leitura ancorada na dimensão do sintoma, pois suas lacunas desconhecidas já estão conscientes por uma falsa consciência esclarecida, de modo que não se estabelece mais um confronto com o que ele tem de reprimir para se organizar, para preservar sua coerência - a razão cínica leva antecipadamente em conta essa distância, de modo que a própria mentira é vivenciada como verdade.

Contudo, é preciso estabelecer uma distinção entre o sintoma e a dimensão da fantasia, pois a versão da sociedade pós-ideológica é apressada em demasia em suas conclusões: “A razão cínica, com todo o seu desprendimento irônico, deixa intacto o nível fundamental da fantasia ideológica, o nível em que a ideologia estrutura a própria realidade social” (ZIZEK, 1996B, p. 314).

Desse modo, segundo Zizek (1996B), o clássico caso marxista do "fetichismo da mercadoria", mais uma vez é um interessante modelo de análise. Neste caso o dinheiro é apenas uma incorporação, uma condensação, uma materialização de uma rede de relações sociais, de modo que o fato de ele funcionar como equivalente universal no palco de troca de todas as mercadorias é ocasionado por sua posição na trama das relações sociais. Mas, a função de ser a encarnação da riqueza aparece aos olhos dos participantes do mercado como se o dinheiro em si, em sua materialidade imediata, já incorporasse naturalmente a riqueza. Entretanto, temos que considerar que a distorção é constituída no próprio fazer da realidade social. O equívoco da formulação marxista é que ela ignora uma ilusão, uma distorção que já está em funcionamento na própria dinâmica da realidade social, no plano do que os indivíduos fazem e não do que pensam ou sabem estar fazendo:

O problema é que, em sua atividade social, naquilo que fazem, eles agem como se o dinheiro, em sua realidade material, fosse uma encarnação imediata da riqueza como tal. Eles são fetichistas na prática e não na teoria. $\mathrm{O}$ que "não sabem", o que desconhecem, é o fato de que, em sua própria realidade social, em sua atividade social - no ato de troca de mercadorias -, estão sendo guiados pela ilusão fetichista (ZIZEK, 1996B, p. 315). 
Portanto, é preciso encontrar uma nova maneira de ler a fórmula marxista "disso eles não sabem, mas o fazem". É preciso dar-se conta de que a ilusão está em primeiro lugar do lado da própria realidade, do que as pessoas fazem. Assim, o que as pessoas desconhecem é a ilusão que estrutura sua atividade social, de modo que sabem muito bem como as coisas realmente são e funcionam, mas continuam a agir como se disso não soubessem. "A ilusão, portanto, é dupla: consiste em passar por cima da ilusão que estrutura nossa relação real e efetiva com a realidade. E essa ilusão desconsiderada e inconsciente é o que se pode chamar de fantasia ideológica" (ZIZEK, 1996B, p. 316).

Esta é uma fantasia inconsciente que estrutura nossa própria realidade social. É tendo presente esta dimensão que se pode dizer que a distância cínica é apenas um modo de permanecer cego para o poder estruturador da fantasia ideológica: mesmo que mantenhamos uma distância irônica ou sarcástica, mesmo que não levemos a sério as coisas, mesmo que saibamos que em nossa atividade estamos seguindo uma ilusão, continuaremos a fazê-la da mesma forma. Se a ilusão estivesse simplesmente pelo lado do saber a postura cínica seria realmente pós-ideológica, sem ilusões, mas como o lugar

da ilusão está na realidade do próprio fazer mediante o poder estruturador da fantasia ideológica inconsciente, o processo ideológico se mantém sutilmente vivo. Assim, por exemplo, as pessoas sabem que sua idéia de Liberdade mascara uma forma particular de exploração [do trabalho], mas, mesmo assim, continuam a seguir essa idéia de Liberdade, movidos que são por uma fantasia ideológica inconsciente (ZIZEK, 1996B).

Por outro lado, cabe aqui ainda ressaltar a objetividade da crença e o poder subversivo da abordagem de Marx que está na maneira como ele estabelece a oposição entre as pessoas e as coisas. A propósito, como observa Zizek (1996B, p. 317):

\begin{abstract}
O sentido da análise de Marx é que as próprias coisas (mercadorias) acreditam em lugar dos sujeitos: é como se todas as suas crenças, superstições e mistificações metafísicas, supostamente superadas pela personalidade racional e utilitarista, se encarnassem nas "relações sociais entre as coisas". Os sujeitos já não acreditam, mas as coisas acreditam por eles.
\end{abstract}

\title{
O ritual ideológico dos gestos repetidos, a crença, a fantasia ideológica e a rede simbólica intersubjetiva alienante
}

De maneira muito singular, segundo Zizek (1996B), foi Blaise Pascal quem já formulou a argumentação de que tão logo se perde a crença a própria configuração do campo social se desintegra. Desse modo, Pascal antecipou a própria definição lacaniana

\begin{tabular}{|l|l|l|l|l|} 
Revista Dialectus & Ano 1 & n. 2 & Janeiro-Junho 2013 & p. 112-137 \\
\hline
\end{tabular}


do inconsciente como o autômato, a letra morta do significante sem sentido e sem significado, que inconscientemente leva a mente consigo. Assim, a absurda "máquina" externa, o automatismo do significante inconsciente, ou seja, a rede simbólica intersubjetiva alienante em que os sujeitos são apanhados, antes de qualquer convicção e escolha, imprime um forte condicionamento à interioridade de nosso raciocínio. Por isso não devemos alimentar enganos e ilusões a respeito de nós mesmos: "Somos tanto autômato quanto mente (...). As provas convencem apenas a mente; o hábito fornece as provas mais sólidas, e aquelas em que mais se acredita. [O hábito] dobra o autômato, que inconscientemente leva a mente consigo" (PASCAL apud ZIZEK, 1996B, p. 318).

A resposta incisiva de Pascal para aquele que tem dificuldades para crer consiste em sugerir-lhe que se submeta de corpo e alma ao ritual ideológico e deixe de lado a argumentação racional: "Entorpeça-se repetindo os gestos sem sentido, [faça a genuflexão e o sinal da cruz, seguindo o costume], aja como se já acreditasse [sem explicações], e a crença virá por si só” (PASCAL apud ZIZEK, 1996B, p. 320).

Dentro desta perspectiva a Lei é sem sentido em seu modo constitutivo, mas a sua estrutura inconsciente diz que devemos obedecer a ela, não porque seja justa, sábia benevolente e civilizadora, mas simplesmente porque ela é a lei, residindo o fundamento último de sua autoridade em seu processo de enunciação inconsciente: "O costume é a eqüidade inteira, pela simples razão de que é aceito. É essa a base mística de sua autoridade. Qualquer um que tente levá-lo de volta a seu princípio original o destruirá” (PASCAL apud ZIZEK, 1996B, p. 318).

Como observa Zizek (1992), a posição de Pascoal não é equiparável a qualquer proto-behaviorismo, pois a mensagem mais profunda da diretiva pascalina é que no momento em que os indivíduos passam a acreditar através das práticas da oração, da genuflexão e do sinal da cruz, eles também verão retrospectivamente que o ato de orar e de ajoelhar-se foi consequência do fato de que eles já acreditavam de alguma forma, sem que eles soubessem ou tivessem consciência disso. Sob o prisma pascalino, estabelecese, portanto, não apenas a importância do conhecimento e da materialidade das instituições, mas também a relevância da "interioridade" e da prática na constituição da crença política por si só.

As práticas da crença sob a forma de rituais e costumes, no entanto, só são efetivas em termos de consolidação da crença, porque um processo de transferência inconsciente garante a repetição do círculo vicioso da crença.

Argumentando de modo ainda mais preciso a este respeito, Zizek observa:

\begin{tabular}{|l|l|l|l|l|} 
Revista Dialectus & Ano 1 & n. 2 & Janeiro-Junho 2013 & p. 112-137 \\
\hline
\end{tabular}




\begin{abstract}
O que [é recalcado] “(...) não é a origem obscura da Lei, mas o próprio fato de que a Lei não tem que ser aceita como verdadeira, mas apenas como necessária - o fato de que sua autoridade é desprovida de verdade. A ilusão estrutural necessária que move as pessoas a acreditarem que a verdade pode ser encontrada nas leis descreve, precisamente o mecanismo da transferência que é a suposição de uma Verdade, de um sentido por trás da realidade estúpida, traumática e incoerente da Lei. A "transferência" é o nome do círculo vicioso da crença: as razões por que devemos acreditar só são persuasivas para os que já acreditam (ZIZEK, 1996B, p. 319-320).
\end{abstract}

As explicações racionais que ajudam a consolidar as crenças e a obediência aos mandamentos religiosos só se apresentam para aqueles que já acreditam, de modo que as razões somente confirmam a crença porque ela já é anteriormente vivenciada e praticada. Como argumenta Zizek (1996B, p. 319):

\begin{abstract}
A obediência "externa" à Lei, portanto, não é a submissão à pressão externa, à chamada "força bruta" não ideológica, mas sim a obediência ao Mandamento na medida em que ele é (...) não compreendido (...) e conserva um caráter "traumático", "irracional”: longe de esconder sua autoridade plena, esse caráter traumático e não integrado da Lei é uma condição positiva dela. É esse o aspecto fundamental do conceito analítico de supereu: uma injunção vivenciada como traumática e "absurda" - isto é, que não pode ser integrada no universo simbólico do sujeito. Mas, para que a Lei funcione "normalmente", esse fato traumático de que "o costume é a eqüidade inteira, pela simples razão de que é aceito" - [que coloca] a dependência da Lei em relação a seu processo de enunciação [inconsciente], ou, [aponta] (...) seu caráter radicalmente contingente - deve ser recalcado no inconsciente, através da experiência ideológica imaginária do "sentido" da Lei, de sua fundamentação na Justiça, na Verdade.
\end{abstract}

O caráter externo da máquina simbólica que funciona como um verdadeiro automatismo significante, como uma aparelhagem maquinal estatal e social, é ao mesmo tempo o lugar em que o destino de nossas crenças mais sinceras e "íntimas", é encenado e decidido de antemão. Quando nos sujeitamos à máquina ou ao aparelho do ritual religioso, por exemplo, de antemão, sem o saber, já acreditamos nas crenças em jogo. Nossa crença já se materializa no ritual externo inconscientemente, e é precisamente desde o caráter externo da máquina simbólica que é possível explicar o status do inconsciente como sendo radicalmente externo - o de uma letra morta. Como observa Zizek (1996B, p. 321): “A crença é uma questão de obediência à letra morta e não compreendida. Esse curto circuito entre a crença íntima e a 'máquina' externa constitui o núcleo mais subversivo da teologia pascalina”.

Na versão pascalina, a máquina simbólica, o automatismo significante, ou o que seria o "Aparelho ideológico de Estado" (Althusser) em uma versão mais moderna, comporta um vínculo com a interpelação ideológica em Pascal, que permite a

\begin{tabular}{|l|l|l|l|l|} 
Revista Dialectus & Ano 1 & n. 2 & Janeiro-Junho 2013 & p. 112-137 \\
\hline
\end{tabular}


internalização subjetiva do automatismo maquinal, produzindo o efeito da crença ideológica numa Causa e o efeito de interligação da subjetivação, do reconhecimento da posição ideológica que cada um ocupa. A propósito, na linha da reflexão pascalina (e não na versão de Althusser, que não conseguiu discernir adequadamente o vínculo entre os Aparelhos ideológicos de Estado e a interpelação ideológica, visto que também não discerniu o que é constitutivo da lacuna entre o Aparelho ideológico e sua internalização): “Essa 'máquina' externa dos Aparelhos ideológicos de Estado só exerce sua força na medida em que é vivenciada, na economia inconsciente do sujeito, como uma injunção traumática e sem sentido [sem significado]"'(ZIZEK, 1996B, p. 321).

A internalização da máquina simbólica, que ocorre por uma necessidade estrutural, nunca será coroada de pleno êxito, como nos ensina Pascal, pois sempre se mantém "um resíduo, um resto, uma mancha de irracionalidade e um absurdo traumático" que se agarra a essa internalização:

Esse resto [espectral], longe de prejudicar a plena submissão do sujeito à ordem ideológica, é a própria condição dela: é precisamente esse excedente não integrado de trauma (...) que confere à Lei sua autoridade incondicional (ZIZEK, 1996B, p. 321).

O sujeito barrado lacaniano (\$), antes de ser capturado por uma interpelação e antes de ser captado na identificação, no reconhecimento/desconhecimento simbólico que possibilite a identificação subjetiva com uma grande Causa em correspondência com o chamamento do "Outro" lacaniano -, ele é captado pelo Outro (a máquina significante) através de um paradoxal objeto-causa do desejo em meio a isso, (o objeto pequeno a, para sempre perdido), mediante o segredo supostamente oculto no Outro:

$\$ \diamond a$ - a fórmula lacaniana da fantasia. Isso também significa que de acordo com a concepção fundamental de Lacan, existe a possibilidade de o sujeito adquirir alguns conteúdos, algum tipo de consistência positiva, fora do "Grande Outro" - fora da rede simbólica intersubjetiva alienante. Essa outra possibilidade é a oferecida pela fantasia, equacionando o sujeito com um objeto da fantasia. Outro aspecto a ser considerado aqui é que a fantasia ideológica é uma função que envolve tanto o Imaginário como o Real. O "Real imaginário" é algo insondável que permeia as coisas com um pedaço do sublime (cf. ZIZEK, 1996B, p. 321-322).

A propósito, o Imaginário encontra-se situado ao nível da relação do sujeito consigo mesmo. É como o olhar do Outro na fase do espelho. Manifesta-se aí uma falta nesse reconhecimento ilusório de si mesmo. Ademais, cabe considerar que o Imaginário é a fantasia fundamental que é inacessível à nossa experiência por ser aquela fantasia

\begin{tabular}{|l|l|l|l|l|} 
Revista Dialectus & Ano 1 & n. 2 & Janeiro-Junho 2013 & p. 112-137 \\
\hline
\end{tabular}


que se eleva do espectro fantasmático em que encontramos objetos de desejo. Enfim, o Imaginário e a fantasia a partir dele projetada nunca podem ser agarrados, porque todo discurso sobre eles sempre estará localizado no Simbólico.

Por outro lado, aquilo que é chamado de "realidade" também é articulado através da significação (o Simbólico) e da padronização característica das imagens (o Imaginário). O que diferencia estes dois registros, visto que ambos funcionam dentro da ordem da significação, é que, enquanto o primeiro, o Simbólico, é aberto em princípio, o segundo, o Imaginário, procura domesticar o Simbólico, prendendo-o em torno de certas fantasias e impondo uma paisagem fantasística peculiar, com seu específico cunho ideológico, a cada indivíduo.

Por fim cabe ainda destacar que Zizek, distingue entre o Real real (que seria a Coisa horrenda, a cabeça de medusa, o abismo e a monstruosidade), o Real simbólico (que seriam, por exemplo, as fórmulas da física quântica não traduzíveis no horizonte da significação, mas que simplesmente funcionam na abordagem científica) e o Real imaginário, que designa não a ilusão do Real, mas o Real da própria ilusão. Trata-se neste último caso não de um Real implacável, mas de um Real frágil que apresenta um traço elusivo traumático, trágico ou místico totalmente insubstancial, mas que incomoda, por ser o ponto do Real no Outro. Enfim, nestas três formas de manifestação do Real: “A questão não é que o Real seja impossível, mas que o impossível é Real" (ZIZEK, 2006, p. 87-89).

\section{Para concluir: ato político e educacional para a emancipação em Slavoj Zizek}

Segundo Zizek, o ato político - e em consequiência, também o ato educativo com vistas à emancipação - somente pode ocorrer quando o pensamento e a ação do sujeito se desprendem das coordenadas da rede simbólica alienante, e se atam à atividade coletiva, traduzindo-se em uma ação educativa e política soberana, sem fixação institucional imediata às imposições do "status quo" e solto das exigências pragmáticas de adaptação às diretrizes do poder constituído, as quais tendem a travar a emergência e a potência de uma linguagem, de um discurso e de uma práxis efetivamente de emancipação. Assim, o ato político-pedagógico crítico instaura sua própria legalidade, suspendendo a Lei do poder opressor imperante, abrindo espaços para a criatividade e a instauração de um processo de emancipação econômico-social, cultural e política.

\begin{tabular}{|l|l|l|l|l|} 
Revista Dialectus & Ano 1 & n. 2 & Janeiro-Junho 2013 & p. 112-137 \\
\hline
\end{tabular}


Ademais, como consequiência de um processo de desarticulação e esvaziamento das amarras paralisantes do sujeito - implicadas com seus nós sintomático-patológicos e com a rede de significantes mestres alienantes, que funcionam como verdadeiros objetos sublimes da ideologia - é suposto um processo de destituição subjetiva, seguido por uma re-subjetivação amparada em insígnias simbólicas sintonizadas com atos políticoeducativos voltados para a liberdade e a emancipação social.

A leitura de Zizek a respeito do ato político (com sua consequência educacional) se apóia sobre a negatividade hegeliano-lacaniana que, a princípio, não encarna nenhuma substância positiva inicial. Ela, parte, antes da irredutibilidade negativa do inconsciente que no sujeito se define por resistir aos processos de identidade e de auto- reflexão. Ou seja, sob este prisma, o sujeito denota uma partícula de liberdade, que é intrinsecamente política e pedagógica, se encontrando em uma situação sempre aberta de não adequação plena a seus papéis e identificações sociais.

Sob esta perspectiva é que a negatividade na forma de uma universalidade não substancial, ou seja, na forma de não-adequação pode contrapor-se à falsidade da universalização da política da identidade, veiculada inclusive pelas instituições educacionais adequadas à ideologia do Capital e ao seu componente político de estabilização. Ou seja: "O ato político [e educacional] por excelência é justamente a suspensão desse universal simbólico que nos é dado pelo Capital” (CHEROBINI, 2007, p. 2).

Nesta mesma direção argumentativa, ainda no que se refere ao conceito de ato político [e, em consequência, também pedagógico] de Zizek, cabe observar que o autor não sacraliza o ato em si, ao colocar importância redobrada ao "dia seguinte", a maneira como o ato rearticula o quadro de mudança crítica, pois o ato apenas como ruptura, ou seja, "o ato sem depois", representaria simplesmente uma pura negatividade (estéril), não positivada. Para Zizek, trata-se do gesto negativo de criar espaços vazios como condição de um ato positivo; trata-se, também, sob este prisma, da relação entre pulsão de morte e sublimação. Em outras palavras, “(...) trata-se da negatividade da pulsão de morte como condição da sublimação positiva" (ZIZEK, 2011, p. 309).

Desse modo, o ato político se reveste de uma verdadeiramente autêntica radicalidade pedagógica, pois não se trata de uma atividade falsa de impotência política que se restringe em de fato apenas reproduzir a constelação sócio-simbólica do capitalismo global existente. E, sob este prisma, todo ato político e pedagógico radical se localiza além de toda a sua condicionalidade, ou seja, ele é incondicional. Assim, não

\begin{tabular}{|l|l|l|l|l|} 
Revista Dialectus & Ano 1 & n. 2 & Janeiro-Junho 2013 & p. 112-137 \\
\hline
\end{tabular}


se trata de um "ato incondicional" situado fora da história e fora do simbólico, mas simplesmente de um ato surpreendente que é irredutível ao parâmetro e à moldura das condições opressivas dadas. Como destaca Zizek (2011, p. 311):

\begin{abstract}
Este ato não só está enraizado em suas condições contingentes, como são essas mesmas condições que fazem dele um ato: o mesmo gesto, realizado num momento errado - cedo ou tarde demais -, [deixa de ser, ou] não é mais um ato. Aqui o paradoxo propriamente dialético é que aquilo que torna o ato "incondicional" é sua própria contingência: se o ato foi necessário, isso significa que foi totalmente determinado pelas condições, e pode ser deduzido a partir delas (como versão ótima a que se chegou pelo raciocínio estratégico, (...). O vínculo entre a situação e o ato político [e pedagógico], portanto, é claro: longe de determinado pela situação (ou de intervir nela a partir de um exterior misterioso), os atos são possíveis em razão do não fechamento ontológico, da incoerência, das lacunas de uma situação.
\end{abstract}

Para Zizek (2011), o capitalismo contemporâneo está atado de forma abstrata ao chamado mercado financeiro com seus fetiches que funciona como acelerador pulsional, fictício e virtual da concentração e centralização capitalista, regulando nestes termos a vida social, com as trocas humanas produtoras de riqueza material e humana deixando de ser cada vez mais o centro dinamizador das relações sociais. Dentro desta moldura perversa de funcionamento do sistema, os desígnios do capital financeiro não podem ser contrariados. E como a crise do capitalismo tornou-se aguda e permanente, impõem-se crescentes sacrifícios à grande maioria da população, com cortes drásticos sendo aplicados em termos de benefícios sociais, de empregos, salários e recursos destinados à saúde e à educação. $\mathrm{O}$ hedonismo consumista presente no capitalismo contemporâneo se insere em um processo de reprodução das relações sociais que não apenas se ancora na exploração da força de trabalho visando a extração da mais-valia, mas, ademais se alimenta de um mais-gozar decorrente do imperativo de gozo obsceno superegóico que prende a intimidade subjetiva das pessoas à versão imaginária do desejo do "grande Outro", ou seja, ao fetichismo da mercadoria como imagem.

Nestes termos nos aproximamos de tempos cada vez mais chocantes e nervosos, mas com os anestesiados cidadãos consumidores das mercadorias como imagem se portando como verdadeiros sonhadores, na perspectiva freudiana do sonhador permanentemente em fuga do encontro com a realidade traumática, de modo a pensar que as coisas podem continuar indefinidamente da mesma forma. Nas condições de crescente crise sistêmica do capitalismo, somos violentamente pressionados a despertar de um sonho noturno e diurno que está se transformando em pesadelo (cf. ZIZEK, 2011). 
O capitalismo globalizado contemporâneo, e junto com ele o formato de sua ideologia e de sua educação sistêmica, anestesiam, paralisam e despolitizam as pessoas para que elas não abracem um projeto político de sociedade que enalteça a importância dos bens públicos e sociais coletivos e o espaço público aberto à participação efetiva do conjunto da população, principalmente dos trabalhadores comuns e dos marginalizados sociais. Sob este prisma, nas atuais condições de sua alienação e impotência política, as pessoas antes são capazes de imaginar o fim do mundo do que o fim do capitalismo.

Nos moldes da ideologia cínica atual as pessoas são pouco suscetíveis a crenças e utopias sociais visualizadoras de um mundo melhor. Ao contrário, preferem ficar imobilizados em termos da crença nos "outros supostos crer e saber": as autoridades políticas, econômico-administrativas, o mercado financeiro e as informações filtradas e manipuladas da mídia, que acreditam crer e saber por elas (cf. ZIZEK, 2010).

A propósito, a democracia, os veículos de comunicação e a educação oficial aparecem completamente subsumidos às pressões e às razões do mercado, mesmo que estejamos testemunhando, hoje, que a rota frenética do sistema, com seus crescentes sintomas sociais patológicos, está se aproximando de um caminho acelerado de autodestruição. E, desse modo, uma educação com uma perspectiva de emancipação não pode ficar neutra e alheia a uma ação política que aponte para a ruptura radical com as coordenadas opressivas inerentes ao funcionamento do sistema capitalismo em crise.

Para finalizar, cabe observar que o ato político e pedagógico de ruptura heróica, corajoso e alternativo ao "status quo" também só é possível porque de acordo com a leitura lacaniano-hegeliana de Zizek (1996B, p. 324):

Existe uma possibilidade de o sujeito obter alguns conteúdos, algum tipo de consistência positiva, fora do 'grande Outro', fora da rede simbólica intersubjetiva alienante. Essa outra possibilidade é a oferecida pela fantasia, equacionando o sujeito com um objeto da fantasia.

Ou seja, o sujeito adquire suas características particulares não apenas por um mandato simbólico que lhe é imposto por uma rede de relações intersubjetivas da qual ele faz parte - porque se assim fosse, o sujeito não passaria de um mero vácuo, um espaço vazio a ser totalmente preenchido pelo conteúdo do "grande Outro" e pelos "pequenos outros", o que resultaria em uma alienação radical e inexorável do sujeito. Assim, a espinha dorsal da "realidade de fantasia" do sujeito de alguma forma mantém uma conexão com o "Real" do desejo do sujeito, dando uma consistência positiva a ele fora da rede simbólica alienante, assim também abrindo brechas para a emergência de atos políticos e pedagógicos de liberdade e de superação das cristalizadas formas de

\begin{tabular}{|l|l|l|l|l|} 
Revista Dialectus & Ano 1 & n. 2 & Janeiro-Junho 2013 & p. 112-137 \\
\hline
\end{tabular}


alienação subjetiva e intersubjetiva, enfim de emancipação individual e coletiva, no plano social, político e cultural.

\section{Referências Bibliográficas}

CHEROBINI, Demétrio. Internet e possibilidades de emancipação: uma reflexão a partir do pensamento de Slavoj Zizek (Texto escrito e apresentado na DCG: Novas Tecnologias e Cibercultura - Julho de 2007). Disponível em: http://www.angelfire.com/sk/holgonsi/demetrio.html

ZIZEK, Slavoj. Em Defesa das Causas Perdidas. São Paulo: Boitempo, 2011.

Como Ler Lacan. Rio de Janeiro: Zahar, 2010.

A Visão em Paralaxe. São Paulo: Boitempo, 2008.

Introdução: O espectro da ideologia. In: et. al. (org.). Um

Mapa da Ideologia. Rio de Janeiro: Contraponto, 1996A, p .7-38.

Como Marx inventou o sintoma?. In: et. al. (org.). Um

Mapa da Ideologia. Rio de Janeiro: Contraponto, 1996A, p.297-331.

. Eles não sabem o que fazem: o sublime objeto da ideologia. Rio de Janeiro: Jorge Zahar Editor, 1992.

\& DALY, Glyn. Arriscar o Impossível: conversas com Zizek. São Paulo: Martins Fontes, 2006. 